\title{
LA GESTIÓN COMUNITARIA \\ COMO HERRAMIENTA ESENCIAL EN LA PROTECCIÓN Y CONSERVACIÓN DEL PATRIMONIO ARQUEOLÓGICO
}

\author{
Community management as an essential tool \\ in protection and conservation of archaeological heritage \\ María Gabriela Arroyo Wong \\ Universidad de Costa Rica, Costa Rica \\ mariagabriela.arroyo@ucr.ac.cr
}

Recibido: 25-08-2017

Aprobado: 03-10-2017

\section{RESUMEN}

María Gabriela Arroyo Wong es "Revalorización" se convierte en un concepto clave cuando de licenciada en Antropología con conservación y protección del Patrimonio Cultural y énfasis en Arqueología específicamente del Patrimonio Arqueológico se habla. En este (Universidad de Costa Rica) y camino la gestión comunitaria es una herramienta esencial ya magíster en Gestión Ambiental y que permite la integración comunidad - patrimonio. La Ecoturismo (Universidad de participación activa de los miembros de las comunidades Costa Rica). Investigadora en desemboca en un proceso real de identificación para con el temas de arqueología, gestión patrimonio y por ende en acciones y procesos que se del patrimonio, incorporación mantengan a largo plazo.

del patrimonio arqueológico al ecoturismo. Docente e Palabras clave: arqueología; patrimonio; gestión; comunidad Investigadora de la Escuela de Antropología de la Universidad ABSTRACT de Costa Rica. A cargo del proyecto de investigación "Revaluing" become a key concept when discussing the "Arquitectura del Monumento conservation and protection of a Cultural Legacy, particularly Nacional Guayabo: Archeological Legacy. When moving toward this goal, caracterización, ubicación y community governance and management is an essential tool contextualización". that permits the integration of community-legacy. The active participation of all community members opens up a true process of identification of and with the legacy and as a result in actions and processes that can be maintained over time.

Keywords: archeology; cultural legacy; management; community

\section{Introducción}

Poco a poco las comunidades en las cuales existe la presencia de elementos arqueológicos han mostrado inquietud por poseer un mayor conocimiento y por ser parte de los procesos de gestión del mismo. Es decir, por su apropiación, no sólo por el interés de la preservación, sino 
también por los beneficios a nivel de la economía local que esto puede significar.

Ante este panorama, es necesario fortalecer las estructuras existentes para trabajar de la mano con las comunidades y de esta manera no generar efectos negativos ni para el patrimonio ni para los vecinos de la zona, "se debe fomentar la protección, conservación y uso racional de los elementos culturales, utilizándolos a su vez como impulsores de microeconomías en las comunidades aledañas." (Arroyo, 2016, p.2).

El concepto de gestión tiende a ser muy amplio, pero puede concebirse como:

...el proceso mediante el cual se realizan una serie de acciones dirigidas al manejo integral del sistema ambiental (incluidos los sitios arqueológicos), tiene el objetivo de lograr un equilibrio adecuado para la protección, el desarrollo económico, uso sostenible e integración de los diversos elementos que lo componen (Arroyo, 2016, p.2).

Asociado a lo anterior se deben incorporar otras variables que ayuden a fortalecer los procesos de identidad como lo es el sistema educativo formal, a través del cual no sólo se brinda el conocimiento, también se puede fomentar el proceso de identificación y por ende de conservación de la evidencia arqueológica.

La importancia de una participación activa de la comunidad, radica en el bagaje de conocimientos que de sus miembros se pueden desprender, y de esta manera enriquecer no sólo los datos científicos obtenidos a través de la investigación. "La recuperación del patrimonio es de suma importancia, ya que la vinculación de la gente con su historia es parte fundamental en el desarrollo, no sólo a nivel individual, también comunal y regional" (Arroyo, 2016, p.6).

\section{El Patrimonio Cultural: de todos y para todos}

Según la Declaración de la UNESCO de 1982, derivada de la "Conferencia Mundial sobre las Políticas Culturales", Ilevada a cabo en México:

...la cultura puede considerarse actualmente como el conjunto de los rasgos distintivos, espirituales y materiales, intelectuales y afectivos que caracterizan a una sociedad o un grupo social. Ella engloba, además de las artes y las letras, los modos de vida, los derechos fundamentales al ser humano, los sistemas de valores, las tradiciones y las creencias... (UNESCO, 1982, p.1). 
Bajo esta definición se enmarca la vida cotidiana de las comunidades y todo aquello que las caracteriza, por lo que la cultura se manifiesta desde diferentes perspectivas. Asimismo, posee características como el hecho de transmitirse de generación en generación, de ser dinámica y transformarse de manera constante.

De esta manera, se va conformando y consolidando el patrimonio cultural en sus diferentes facetas. Este debe tener una característica esencial y es que la comunidad los asuma como parte de su identidad, que lo sienta suyo. Así, se establece que "el patrimonio cultural de cada pueblo, (está) integrado por los objetos culturales que mantienen vigentes, bien sea con su sentido y significado originales, o bien como parte de su memoria histórica" (Bonfil, 2004, p.119).

\section{El Patrimonio Arqueológico: manejo sostenible, oportunidad para todos}

El concepto de Patrimonio Cultural engloba el de Patrimonio Arqueológico ya que este es parte de la historia de los pueblos, es la conexión tangible con el pasado, un elemento identitario y significativo en la vida cotidiana de muchas personas.

Según el Consejo Internacional de Monumentos y Sitios (ICOMOS), en la Carta Internacional para la Gestión del Patrimonio Arqueológico, en su Artículo 1, el mismo:

\footnotetext{
...engloba todas las huellas de la existencia del hombre y se refiere a los lugares donde se ha practicado cualquier tipo de actividad humana, a las estructuras y los vestigios abandonados de cualquier índole, tanto en la superficie como enterrados, o bajo las aguas, así como el material relacionado a los mismos. (ICOMOS, 1990, p.1)
}

El Patrimonio Arqueológico es parte de la memoria histórica de las comunidades; es por esto que es de suma importancia su protección, conservación y divulgación, ya que de esta manera los individuos pueden revalorizar, identificarse y apropiarse de este para sentir que es parte de su pasado y de esta manera darle un verdadero valor social.

Una de las particularidades de este tipo de patrimonio es que es finito, es una riqueza cultural que se caracteriza por su fragilidad, además de no ser renovable; es por esto que son urgentes medidas que logren su protección 
pero que a su vez no sean una limitante para su conocimiento y aprovechamiento por parte de las comunidades (Arroyo, 2016, p.82).

A su vez, el mismo engloba muchos aspectos que permiten no sólo su contemplación per se, sino que por sus características se torna un recurso social, cultural y económico. Con una adecuada gestión se permitiría a las comunidades una integración con él y de esta manera desarrollar el trinomio identificación, apropiación y aprovechamiento, bajo el marco de la protección y la conservación.

Como afirma el ICOMOS (1990, p.2):

...la protección del patrimonio arqueológico debe incorporarse a las políticas de planificación a escala internacional, nacional, regional y local. La participación activa de la población debe incluirse en las políticas de conservación del patrimonio arqueológico...La participación se debe basar en la accesibilidad a los conocimientos...

Esto indica que debe existir una correcta difusión de los bienes culturales presentes, además de una interpretación integral del contexto donde se hallan, ya que las evidencias arqueológicas son parte de un sistema mucho mayor, que involucra la riqueza natural y la comunidad viva.

\section{Gestión comunitaria: protección y conservación de la mano con las comunidades}

Antes de iniciar los trabajos conjuntos con las comunidades se debe tener muy claro el marco legal que protege el Patrimonio Arqueológico, de esta manera no se incurrirá en falsas expectativas a los vecinos ni en daños al patrimonio.

En el caso específico de Costa Rica, la Ley N6703 Ley sobre Patrimonio Nacional Arqueológico designa como única institución responsable y encargada de los vestigios arqueológicos al Museo Nacional de Costa Rica.

Tomando en cuenta lo anterior, existe la posibilidad de crear espacios idóneos en los que los vecinos también se beneficien de la protección y conservación por medio de proyectos asociados al desarrollo y/o fortalecimiento de su economía local.

La participación activa de las comunidades en procesos de tomas de decisiones o en la implementación de proyectos paralelos a diferentes iniciativas de conservación, puede traer múltiples beneficios; pero es 
indispensable llevar de la mano un proceso integral que permita germinar ideas que nazcan de ellas.

"Los proyectos de desarrollo rural y más aun los que nacen desde el seno de las comunidades se convierten en una herramienta que puede ayudar a inyectarle dinamismo a la economía local, asimismo, al ser propuestas propias, incentivan una mayor participación de las personas" (Arroyo, 2016, p.94).

De esta manera será mucho más atractivo desarrollar proyectos de gestión comunitaria en torno al patrimonio y obtener una participación activa y sostenida a largo plazo.

No se debe olvidar que el recurso patrimonial es de y para la comunidad, es decir,

...se debe enfocar parte importante del trabajo realizado por las instituciones encargadas de su reguardo, a fortalecer o bien crear la relación directa entre patrimonio e identidad comunal; por medio de proyectos relacionados al mismo se pueden obtener actitudes positivas y de cooperación; de esta manera se trabaja en varias direcciones con un mismo interés: proteger, conservar y divulgar el patrimonio arqueológico nacional (Arroyo, 2016, p.95).

\section{El turismo arqueológico ○ arqueoturismo: una opción real para el patrimonio y para las comunidades}

El arqueoturismo o turismo arqueológico abarca más allá de sólo la visitación a lugares donde existan restos culturales, "es una modalidad bajo la que se presentan propuestas y productos culturales y turísticos en los que la arqueología es el ingrediente principal" (Tresserras, 2004, p.2).

El mismo se compone de diversos elementos a través de los cuales se genera riqueza no sólo desde la perspectiva cultural, también con la creación de microeconomías mediante un manejo adecuado y de la participación comunitaria, se refuerza la parte de identidad por medio de la revalorización y conocimiento de ¿qué existe y qué significado tiene la evidencia arqueológica?, además se promueve el respeto por la diversidad y por las sociedades pasadas.

\section{La importancia de saber comunicar: la interpretación como herramienta en el turismo arqueológico}


Al presentar la evidencia arqueológica se debe establecer el lenguaje adecuado para su interiorización y comprensión, bajo esta premisa es que se debe adaptar la información para su divulgación.

Una herramienta fundamental en este objetivo es la interpretación ambiental la cual es una "actividad educativa ambiental que examina y revela de manera atractiva, las características de un área y sus relaciones biofísicas y culturales, a través de experiencias directas que generen en las personas disfrute, sensibilidad, conocimiento y compromiso con los valores interpretados" (Comisión Centroamericana de Ambiente y Desarrollo, 2005, p.1).

La importancia de la comunicación radica en que un mensaje enviado de manera correcta y comprensible, en el caso del Patrimonio Arqueológico, se puede traducir en identificación por parte del que lo observa, lo cual deriva en conservación y protección.

El abrir al público un sitio con evidencias arqueológicas no sólo debe enfocarse en el tipo de elementos que se van a presentar, también debe responder al ¿cómo?, ¿por qué? y a ¿quiénes?

La presentación al público de un lugar de importancia patrimonial (natural o cultural) requiere que desarrollemos un proceso metodológico de análisis y toma de decisiones para llegar al tan deseado resultado final: la "interpretación del patrimonio visitado", o lo que es lo mismo: un público enterado del significado del sitio, apreciándolo y disfrutándolo. (Morales, 2013, p.1).

Es así como la interpretación debe ser un proceso durante el cual se busque lograr un mayor aprecio y por ende disfrute de los visitantes y a su vez la conservación a través de las actitudes generadas en los mismos. Por esto, se debe tener muy claro cuál es el público al que se dirige el atractivo y cuáles son las expectativas que traen consigo.

Como se mencionó, la interpretación va mucho más allá de la exhibición de objetos, sin este proceso es muy posible que las personas que visitan los lugares no interioricen la información que se desprende de la evidencia, ya que muchas veces es presentada a través de palabras técnicas que no se interpretan para los diferentes tipos de público.

Como mencionan Morales y Ham (2008) (citados por Arroyo, 2016, p.89):

cuando decimos que le vamos a interpretar algo al público, en realidad estamos planteándonos tres aspectos: 
1. Les voy a brindar una visión de ese algo, basada en el conocimiento científico,

2. Les voy a traducir para que comprendan mejor ese algo, y

3. Les voy a hacer pensar con respecto a ese algo.

Bajo ese marco, se debe crear un plan estratégico que contemple desde la obtención de la información de manera rigurosa y científica, hasta su presentación en diferentes "lenguajes" para la diversidad de público y sus características. De esta manera, no sólo se piensa en el visitante "extranjero", también se debe involucrar de forma activa a los miembros de las comunidades quienes conviven día a día con el Patrimonio Arqueológico.

Para Freeman Tilden (1957) y Morales (2007) (citados por Arroyo, 2016: p.91), la interpretación se basa en los siguientes principios:

1. La interpretación debe provocar atención, curiosidad e interés en la audiencia: la primera preocupación que debe atenderse es cómo capturar el interés de los visitantes, ya que si no se atrae la atención, será una tarea mucho más difícil la de transmitir el mensaje; se debe recordar que es mucho más fácil perder la atención que capturarla y retenerla; es por esto que se debe poner especial cuidado en los elementos que se utilizan en un área de visitación.

2. Debe relacionarse con la vida cotidiana del visitante: mencionan los autores que la implicancia del "yo" es trascendental, ya que de esta forma se conecta con los esquemas mentales del público, es una manera más fácil de que cada sujeto personalice y retenga la información brindada; una manera es hacer analogías o ejemplos de la vida cotidiana. "No es lo mismo decir: "El perímetro de esta fortaleza es de 950 metros", que, "Si usted recorriese los muros del fuerte, abarcaría casi un kilómetro"'" (Morales, 2007: p.20).

3. Debe revelar la esencia del significado del lugar u objeto: cuando se presenta información a un público general, esta debe filtrarse; ya que la misma proviene de investigaciones científicas, no obstante no siempre se puede transmitir toda la existente. Por lo cual, a través de la interpretación se propone transmitir "el espíritu del lugar", con mensajes breves, concretos y claros que faciliten su comprensión para todo tipo de público.

4. Debe unir las partes de un todo: los sitios arqueológicos forman parte de un todo; un análisis de contexto permitirá relacionar los aspectos tanto naturales como antrópicos presentes. A través de la interpretación se debe lograr un hilo conductor coherente entre 
estos aspectos; presentarlo al público en forma de relaciones y en torno a una idea central que permita esta dinámica.

5. Es un arte, por lo tanto debe producir un impacto en el público: cuando un visitante gusta de lo que observa y le transmite más allá del significado, se generan emociones y sentimientos; por medio de la interpretación se busca no sólo comunicar, también impactar al público y de esta manera que lo conserve más allá de las horas de visita al lugar.

6. La interpretación tiene que intentar ir más allá del mero hecho de la visita: la interpretación tiene el deber de contribuir mediante su implementación a la conservación y protección del patrimonio; ya que es la herramienta que da el valor de uso social al objeto, generando impactos positivos en el público y por ende, acciones positivas del mismo.

\section{Áreas públicas: apropiación del espacio para la divulgación del Patrimonio Arqueológico}

Las áreas públicas o comunes como parques, zonas verdes, áreas recreativas, etc., se tornan espacios esenciales para la divulgación y recordatorio constante de la existencia de la riqueza arqueológica en las comunidades.

El aprovechamiento de dichos espacios es idóneo para revitalizar la memoria histórica, el uso de vallas informativas que muestren a la comunidad y a los visitantes los elementos existentes, mediante un lenguaje atractivo y comprensible para la diversidad de público, puede cumplir varios objetivos:

1) visibilizar la riqueza arqueológica de la zona,

2) informar sobre el patrimonio arqueológico existente,

3) educar en torno al patrimonio arqueológico,

4) promover la identificación y apropiación del patrimonio arqueológico por parte de las comunidades,

5) orientar en cuanto a medidas de protección y conservación del patrimonio arqueológico.

Este tipo de lugares poseen características importantes que benefician a la divulgación del Patrimonio, son espacios donde se reúnen los vecinos a interactuar, generalmente son áreas que visitan los turistas, por lo cual se pueden considerar puntos estratégicos. 
Se debe dar la oportunidad a la comunidad de participar en esta dinámica de comunicación, por ejemplo, a través de los niños de escuela o estudiantes de los colegios, invitándolos a participar en la elaboración de afiches en torno a la temática para posteriormente exhibirlos en estos espacios.

De esta manera, los vecinos se integran y participan de manera activa en la gestión de los sitios y evidencias arqueológicas.

Finalmente, como se ha tratado de mostrar, la participación constante y permanente de los miembros de las comunidades desde diferentes perspectivas (escolares, colegiales, adultos mayores, mujeres, etc.) enriquece enormemente la visión del Patrimonio Arqueológico, tomar en cuenta y valorar las opiniones e ideas para la implementación de proyectos que también los beneficien, se transforma en la plataforma más fuerte si nos dirigimos de manera efectiva a la meta de la conservación y protección del Patrimonio Cultural. 


\section{BIBLIOGRAFÍA}

Arroyo, Gabriela. (2016). Incorporación del patrimonio arqueológico como elemento impulsor de proyectos ecoturísticos en las comunidades de Palmar Norte, Palmar Sur, Sierpe (Cantón de Osa, Puntarenas). Tesis para optar al grado y título de Maestría Académica en Gestión Ambiental y Ecoturismo. Posgrado en Gestión Ambiental y Ecoturismo. Universidad de Costa Rica.

Bonfil, Guillermo. (2004). Pensar nuestra cultura: Nuestro patrimonio cultural: un laberinto de significados. En: Diálogos en la acción, primera etapa. México.

Comisión Centroamericana de Ambiente y Desarrollo. (2005) Manual de Interpretación Ambiental en Áreas Protegidas de la Región del Sistema Arrecifal Mesoamericano. Belice.

ICOMOS. (1990). Carta Internacional para la gestión del Patrimonio Arqueológico. Canadá.

Morales, Jorge. (2007). La interpretación en contexto. En: Fernández Balboa, Carlos (ed.) La interpretación del Patrimonio en La Argentina: Estrategias para conservar y comunicar nuestros bienes naturales y culturales. Capítulo 1: pp. 17-21. Primera Edición Administración de Parques Nacionales. Buenos Aires, Argentina.

Morales, Jorge. (2013). La Planificación Interpretativa asegura la excelencia en interpretación: Una herramienta para el turismo, la difusión in situ del patrimonio y la puesta en valor de lugares de interés: parques naturales, yacimientos arqueológicos, jardines botánicos, sitios históricos, cascos urbanos y otros. Algeciras, España.

Morales, Jorge; Ham, Sam. (2008). A qué interpretación nos referimos. En: Boletín de Interpretación N¹9. Asociación para la Interpretación del Patrimonio. España.

Tilden, Freeman. (1957). Interpreting Our Heritage. The University of North Carolina Press, Chapel Hill. United States. 
Tresserras, Jordi. (2004.) El arqueoturismo o turismo arqueológico: un paso más para la valorización del patrimonio arqueológico. En: Boletín GC: Gestión Cultural N9: Turismo Arqueológico. España.

UNESCO. (1982). Declaración de México sobre las políticas culturales. Conferencia Mundial sobre las Políticas Culturales. México. 
